\title{
Surgery for the low-birth-weight infant with congenital heart disease: Where is the problem?
}

\author{
Thomas L. Spray, MD
}

See related article on pages 2499-506.

In this issue of the Journal, Kalfa and associates ${ }^{1}$ from Columbia University describe their experience with surgical repair of congenital heart disease in patients weighing less than $2.5 \mathrm{~kg}$. This study shows excellent results in the small patient population with an overall mortality of $10.9 \%$, a mortality rate that is lower than in most reported series.

The group of patients weighing less than $2.5 \mathrm{~kg}$ at surgical intervention was compared with a group weighing 2.5 to $4.5 \mathrm{~kg}$ at the same institution to determine the potential role played by prematurity, STAT risk category, univentricular or biventricular pathway, and timing of surgery over a 6year period from 2006 to 2012. Hospital mortality was significantly higher in the low birth weight group at $10.9 \%$ versus $4.8 \%$ in a group of infants weighing 2.5 to $4.5 \mathrm{~kg}$. Postoperative length of stay, unplanned reintervention rates, and late mortality were not different between the 2 groups; however, follow-up was short. Early outcomes were not dependent on STAT risk categories, univentricular or biventricular pathway, or timing of surgery, although these factors were associated with outcomes in the higher weight group. Lower gestational age at birth was an independent risk factor for early mortality in the small birth weight group.

Kalfa and associates ${ }^{1}$ suggest that the use of a dedicated neonatal intensive care unit for the management of low birth weight patients may have an effect on outcome and partially explain the excellent results in this series along with a dedicated and highly experienced surgical team.

Many studies have shown that the risk of surgical intervention for low birth weight neonates is significantly higher among essentially all risk categories than in higher birth weight infants. ${ }^{2-5}$ This has been supported by analysis of the Society of Thoracic Surgeons Database and by multiple reports from other institutions with high-volume

\footnotetext{
From the Department of Cardiothoracic Surgery, Children's Surgical Associate, Ltd, Philadelphia, Pa.

Disclosures: Author has nothing to disclose with regard to commercial support.

Received for publication Oct 20, 2014; accepted for publication Oct 20, 2014.

Address for reprints: Thomas L. Spray, MD, Department of Cardiothoracic Surgery, Children's Surgical Associate, Ltd, 34th St and Civic Center Blvd, Philadelphia, PA 19104 (E-mail: spray@email.chop.edu).

J Thorac Cardiovasc Surg 2014;148:2468-9 $0022-5223 / \$ 36.00$

Copyright $₫ 2014$ Published by Elsevier Inc. on behalf of The American Association for Thoracic Surgery

http://dx.doi.org/10.1016/j.jtcvs.2014.10.090
}

cardiac surgical programs. ${ }^{6}$ When examining the data, it seems that the delay of surgical intervention to gain arbitrary weight is not associated with better outcome, as suggested by Toronto and other centers. ${ }^{7}$ In this excellent study from New York, ${ }^{1}$ the low birth weight patients undergoing even complex univentricular surgical pathways had a low operative mortality and in some cases even better outcomes than the higher birth weight group. Thus, it seems that the type of cardiac repair or the use of cardiopulmonary bypass may not necessarily be a primary risk factor for mortality in the low birth weight subgroup.

The data that are now being accumulated, as experience increases in surgical intervention in low birth weight infants, suggest that surgeons are capable of performing complex operations in even very small babies. Thus, the technical aspect does not seem to be the primary problem, although there is certainly a benefit in a meticulous repair that does not lead to a need for reintervention in the postoperative period. Early reintervention has been associated with significant morbidity and mortality in several series. Perhaps our definitions of low weight should be lowered to $2.0 \mathrm{~kg}$ or less to better identify those neonates at greatest risk from the technical issues at operation, of hemorrhage from coagulopathy, and of intracranial bleeding.

If the surgical technical aspects can be mastered, then the increase in mortality must lie in more patient-related factors or other systems issues. Kalfa and associates ${ }^{1}$ speculate that perhaps the use of a dedicated neonatal intensive care unit could improve outcomes in these very small infants, although the study cannot actually address this particular issue. Of note, Kalfa and associates suggest that lower gestational age is more important than birth weight in terms of increasing mortality, although other reports dispute this finding. Other studies have shown that many children with congenital heart disease born at term have maturational development of the brain and other organs that is more consistent with prematurity of 35 to 36 weeks. ${ }^{8}$ Thus, these premature babies may be even more immature than their gestational age. It then becomes logical to consider whether the strategies to delay birth to later gestational age might improve overall outcomes by mitigating the effects of prematurity. Unfortunately, studies have suggested that the incidence of prematurity is increased in patients with congenital heart disease and that the rate of spontaneous preterm labor is higher in this patient population. ${ }^{9}$ Thus, in more cases the mother is delivering prematurely spontaneously rather than by a planned cesarean section. This makes it difficult to find strategies to delay birth to a later 
gestational age. In addition, there are no good data to suggest that delaying preterm birth actually results in greater development in utero. Patients may "stall" in their development during the later phases of gestation such that additional time before birth may not actually improve organ function. Perhaps our focus should be placed on strategies to treat the fetus in utero, to maximize central nervous system and other organ development in the milieu of abnormal placental and fetal flow characteristics.

Most of the studies that have compared outcomes in low birth weight and normal birth weight patients have looked at effects of delay of surgery, effects of cardiopulmonary bypass versus palliative approaches and complete repair, and mortality and postoperative morbidity. Unfortunately, we may be looking at the wrong aspect. If we cannot identify specific patient- related variables that are modifiable, then perhaps rigorous analysis of the mortality causes would lead us to a better understanding of where the risk lies for these patients. If much of the mortality is related to sepsis, multiorgan system failure, respiratory insufficiency, or effects of immature organs on the overall physiology, then these factors will need to be mitigated to improve our overall results. Kalfa and associates ${ }^{1}$ suggestion that better outcomes might be related to dedicated neonatal intensive care unit management is intriguing but would require more information from their center and other centers that use this approach. Certainly, active involvement by specialists in neonatal intensive care in cardiac intensive care units is welcome and beneficial in managing these complex patients; however, many centers have staff with long experience in managing neonates with cardiac malformations even in more dedicated cardiac intensive care unit environments.

Despite the excellent results in this study from Columbia University, ${ }^{1}$ there clearly is a need to do better in surgical treatment of the small birth weight baby. It is becoming apparent that delay of surgical intervention in very low birth weight neonates carries some risk and does not seem to offer a significant benefit over earlier intervention. It also is apparent that interventional or surgical palliative approaches are not necessarily better than complete surgical repairs when a complete repair can be technically accomplished in the small neonate. Thus, more data need to be collected on the effects of patient comorbidities and the environment and postoperative management to attempt to identify those factors that actually account for the observed increased mortality and morbidity in this patient group.

\section{References}

1. Kalfa D, Krishnamurthy G, Duchon J, Najjar M, Levasseur S, Chai P, et al. Outcomes of cardiac surgery in patients less than $2.5 \mathrm{~kg}$ : impact of patient-dependent and patient-independent variables. J Thorac Cardiovasc Surg. 2014;148:2499-506.

2. Azakie A, Johnson NC, Anagnostopoulos PV, Egrie GD, Lavrsen MJ, Sapru A. Cardiac surgery in low birth weight infants: current outcomes. Interact Cardiovasc Thorac Surg. 2011;12:409-14.

3. Swenson AW, Dechert RE, Schumacher RE, Attar MA. The effect of late preterm birth on mortality of infants with major congenital heart defects. J Perinatol. 2012; 32:51-4.

4. Lechner E, Wiesinger-Eidenberger G, Weissensteiner M, Hofer A, Tulzer G Sames-Dolzer E, et al. Open-heart surgery in premature and low-birthweight infants-a single-centre experience. Eur J Cardiothorac Surg. 2009; 36:986-91

5. Reddy VM, McElhinney DB, Sagrado T, Parry AJ, Teitel DF, Hanley FL. Results of 102 cases of complete repair of congenital heart defects in patients weighing 700 to 2500 grams. J Thorac Cardiovasc Surg. 1999;117:324-31.

6. Curzon CL, Milford-Beland S, Li JS, O’Brien SM, Jacobs JP, Jacobs ML, et al Cardiac surgery in infants with low birth weight is associated with increased mortality: analysis of the Society of Thoracic Surgeons Congenital Heart Database. $J$ Thorac Cardiovasc Surg. 2008;135:546-51.

7. Hickey EJ, Nosikova Y, Zhang H, Caldarone CA, Benson L, Redington A, et al Very low birth-weight infants with congenital cardiac lesions: is there merit in delaying intervention to permit growth and maturation? J Thorac Cardiovasc Surg. 2012;143:126-36.

8. Licht DJ, Shera DM, Clancy RR, Wernovsky G, Montenegro LMM, Nicolson SC, et al. Brain maturation is delayed in infants with complex congenital heart defects. J Thorac Cardiovasc Surg. 2009;137:529-36.

9. Laas E, Lelong N, Thieulin AC, Houyel L, Bonnet D, Ancel PY, et al. Preterm birth and congenital heart defects: a population-based study. Pediatrics. 2012;130: e829-37. 